\title{
An Investigation of Co-movements among the Growth Rates of the G-7 Countries
}

Brian M. Doyle and Jon Faust, of the Board's Division of International Finance, prepared this article. Jonathan R. Halket provided research assistance.

Early in 2000, after a decade of economic expansion, growth began to slow in the United States. Over the ensuing months, the growth rates of gross domestic product began to decline simultaneously in many countries, including each of the large, advanced economies that constitute what is known as the Group of Seven (G-7) - Canada, France, Germany, Italy, Japan, the United Kingdom, and the United States. The general slide in real (inflation adjusted) GDP growth seemed striking to many, and it fueled speculation that a period was emerging in which broad movements in the economies of the industrialized countries would be more closely linked. ${ }^{1}$ Proponents of this view argued that the increasing economic integration of the industrial economies brought about by greater trade in goods and financial markets was leading to a greater synchronization of national economies.

If correct, the view that international growth rates are now more closely tied would have important implications for the making of national economic policies. With greater co-movement of GDP, for example, governments would need to take closer account of forecasts for conditions abroad in formulating forecasts for their domestic economies.

This article examines whether the links between U.S. growth and growth of the other G-7 countries have fundamentally changed. We first document the view that economic integration has increased markedly in terms of international trade and the globali-

1. Discussions of this view appeared in the Washington Post, July 18, 2001, p. A1; the New York Times, August 20, 2001, p. A1, and November 25, 2001, p. A12; and the Economist, August 23, 2001, pp. 22-24. Also see Thomas Daalsgaard, Jorgen Elmeskov, and Cyn-Young Park, "Ongoing Changes in the Business CycleEvidence and Causes," Organisation for Economic Co-operation and Development (OECD), Economics Department Working Paper 315 (2002); International Monetary Fund, "Business Cycle Linkages Among Major Advanced Economies," in World Economic Outlook (October 2001), pp. 65-79; International Monetary Fund, "Recessions and Recoveries," World Economic Outlook (April 2002), pp. 104-37; OECD, OECD Economic Outlook, no. 70 (December 2001), pp. 4-5, and no. 71 (June 2002), pp. 141-58. zation of financial markets. The degree to which these factors might be expected to increase the co-movement, or correlation, of economic growth among countries is, however, subject to debate. We turn next to characterizing the historical patterns in this correlation. Our analysis finds, indeed, that the estimated correlation of growth across the G-7 has been higher in the current downturn than during the expansion of the 1990s. However, rather than signaling a future of permanently higher synchronization, this rise is typical of business cycles over the past thirty years. Estimated correlation fluctuates widely over time and has historically risen through U.S. recessions and fallen during expansions. Furthermore, estimates of correlation have not yet reached the peaks attained after earlier recessions.

Although the correlation of growth rates among the G-7 economies does not appear dramatically different now than it was in earlier years, the variability of their growth rates over this period does seem to have generally declined. ${ }^{2}$ All else equal, a fall in variability would imply increased correlation among national growth rates. We discuss the offsetting changes that have left correlation largely unchanged. Overall, despite many changes in the international economy, the evidence does not reveal the arrival of a permanently higher correlation of growth rates among the G-7.

\section{WHY CORRELATION MAY HAVE CHANGED}

The growth rates of national economies fluctuate through time, and the growth rates of the G-7 economies often move similarly to each other but not in lockstep (chart 1). Fluctuations in growth in any economy may arise because of changes in factors such as the productivity of labor and capital, economic policy, business investment spending, and consumption and savings decisions. These changes are called shocks to economic growth. Shocks can give rise to co-movements in growth among countries in

2. Japan, which had a protracted period of slow growth during the $1990 \mathrm{~s}$, is an exception to this conclusion. 
1. Change in real GDP in the United States, and the average change in the other G-7 countries, 1971-2002:Q1

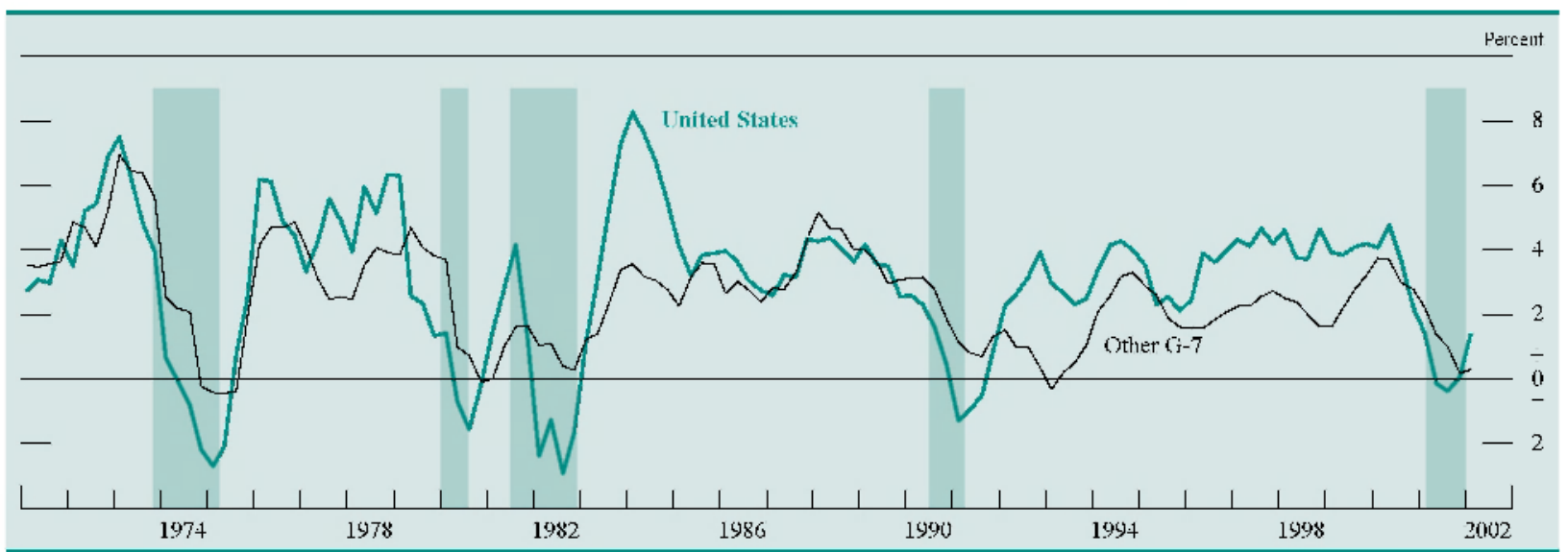

NOTE. The data are quarterly and change is for four quarters. The Group of Seven (G-7) countries are Canada, France, Germany, Italy, Japan, the United Kingdom, and the United States. Shaded bars are periods of recession in the United States as defined by the National Bureau of Economic Research (NBER). Although the shaded bar for the most recent recession ends at

December 2001, the NBER has not, as of this writing, chosen an end-date for that recession.

SOURCE. Here and in the following charts, GDP data are from Haver Analytics.

two basic ways: through linkages among economies and through simultaneous incidence of the shocks. First, a shock arising in one country can be transmitted through various economic and financial linkages to another country. Second, a shock may directly affect several countries at once; a widespread drought, for example, might cause a simultaneous fall in agricultural output in many countries, even in the absence of any linkages across borders.

The reasons that the correlation of economic growth across nations could increase can also be grouped into two types concerning linkages and simultaneous incidence. First, the structure of the world economy could change so that shocks affecting one or more economies are transmitted more strongly to other economies. The proponents of the view that rising economic integration has increased correlation have this reason in mind. A second possibility is that, although the cross-border transmission of shocks is unchanged, the frequency of global shocks has increased or the sensitivity of national economies to those shocks has risen. In this section, we review the reasoning behind each of these two sources of change in correlation.

\section{Increased Cross-Borden Transmission of Shocks}

The links among the economies of the G-7 grew steadily over the final decades of the twentieth century. Each G-7 country except Japan has shown an increase in merchandise trade with its G-7 partners over the period since 1970 (chart 2). As a percentage of its own GDP, Canada's trade with its G-7 partners more than doubled, from about 30 percent to more than 60 percent, with much of the rise coming after the U.S.-Canada Free Trade Agreement in 1989. Although G-7 trade as a share of GDP is lower in the other countries than in Canada, trade shares have nonetheless generally risen. The U.S. share rose from about 5 percent to about 9 percent over the period, and each of the European G-7 nations have now reached shares of about 20 percent.

Financial integration has also increased. For example, the share of foreign equities in U.S. equity portfolios rose from less than 2 percent in the early $1980 \mathrm{~s}$ to almost 12 percent in 2001 (chart 3). The share of U.S. equities in foreign equity portfolios has also risen a great deal over the period. Other measures of international financial market integration show a similar pattern of increase. ${ }^{3}$

A common presumption is that as trade and fināncial market integration increases among nations, their economic growth will become more synchronized. One standard argument about why a rise in goods trade would increase correlation is straightforward: When a surge in demand raises the growth rate in one country, some of the increase in demand will be for imported goods and thereby tend to raise the growth rate of that country's trading partners.

Openness to trade brings other changes that could decrease correlation, however. For example, one of the primary benefits of trade according to economic theory is that it allows each country to specialize

3. International Monetary Fund, "Business Cycle Linkages Among Major Advanced Economies," in World Economic Outlook (October 2001), pp. 65-79; International Monetary Fund, "Recessions and Recoveries," World Economic Outlook (April 2002), pp. 104-37. 
2. Trade (exports plus imports) of each G-7 country with the rest of the G-7 as a share of its own GDP, 1970-2000

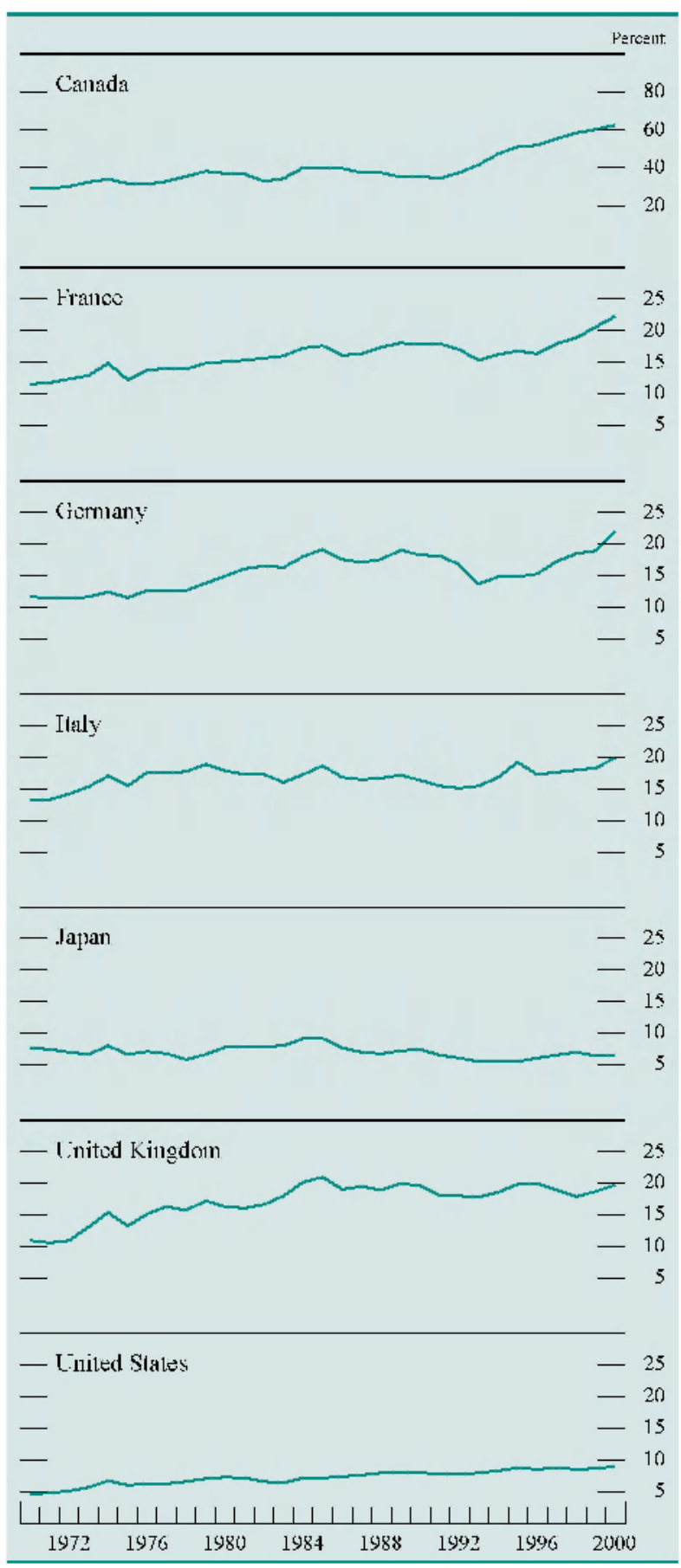

NôTE. The data are annual. Imports, exports, and GDP are in current U.S. dollars at current exchange rates.

SOURCE. International Monetary Fund, Direction of Trade Statistics (various issues); Organisation for Economic Co-operation and Development.

in areas of production in which it has a comparative advantage relative to its trading partners. With increased trade, therefore, nations could come to specialize in certain types of production, relying on
3. Share of foreign equities in equity holdings of U.S. residents and share of U.S. equities in equity holdings of residents of foreign countries, 1980-2002:Q1

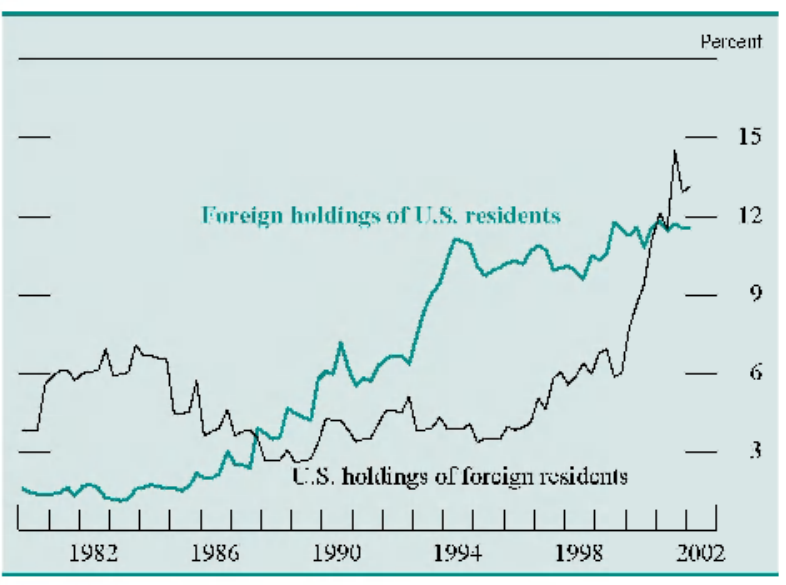

SOURCE. International Finance Corporation; International Federation of Stock Exchanges; Federal Reserve Board.

imports to meet demand for other products. If different types of production are subject to different kinds of shocks, then trade-related specialization could decrease growth correlations. ${ }^{4}$ Trade in goods could decrease output correlations for other reasons as well. ${ }^{5}$

Similarly, increases in financial integration have an ambiguous implication, at least theoretically, for the international correlation of growth rates. On the one hand, if equities of a given country are widely held around the world, a fall in the country's stock market will simultaneously decrease the wealth of consumers in many nations, potentially increasing the correlation in consumer demand and investment, and hence, GDP growth around the world. On the other hand, international diversification of investment portfolios, like increased trade in goods, could contribute to the specialization in production among national economies, which, as noted above, could decrease output correlations."

4. Paul Krugman develops this argument in his "Lessons of Massachusetts for EMU," in Francisco Torres and Francesco Giavazzi, eds., The Transition to Economic and Monetary Union (Cambridge University Press, 1993), pp. 241-69.

5. One such reason is that if countries experience different productivity shocks, increased trade in investment goods can help shift productive capital to more productive countries, magnifying the effects of different shocks. Regarding this effect and also the role that vertical integration can play in raising correlation, see M. Ayhan Kose and Kei-Mu Yi, "International Trade and Business Cycles: Is Vertical Specialization the Missing Link?" American Economic Review, vol. 91 (May 2001), pp. 371-75.

6. For example, production specialization involves risks both to the owners and the employees of the firms. To the extent that these risks can be reduced through diversification in asset markets, one might expect greater specialization. For other examples of ambiguous effects 
While trade in goods and assets are the main ways that economic integration is measured, some analysts have also speculated about less tangible forms of integration that could affect output correlation. For example, some have argued that consumer and investor sentiment in nations across the globe may be more linked now than in the past because of, say, advances in global telecommunications. Because sentiment and its effect on the economy are notoriously hard to measure, this factor is highly speculative.

Some empirical studies provide clearer guidance, however, regarding the net effect of integration on the correlation of growth rates. These studies compare the correlation of GDP growth of regions within a country with similarly situated regions across national boundaries. Because regions within a country are usually quite highly integrated, these comparisons shed light on how integration affects correlation. Such comparisons consistently show that regions within countries have more highly correlated output growth than do national economies or similarly situated regions across national boundaries. ${ }^{7}$

Despite the ambiguities of theory, these empirical results have led most observers to conclude that increasing economic integration to the level found within national borders generally has a net positive effect on output growth correlation. But a separate question is whether the economic integration of the United States and the other G-7 nations has changed enough in, say, the past ten to fifteen years to generate a pronounced increase in correlation. We know of no clear evidence that changes of the magnitude we have observed would significantly raise the correlation of U.S. economic growth with that of the rest of the G-7. ${ }^{\text {. }}$

related to increased capital mobility, see Jeffrey Frankel, "Ambiguous Policy Multipliers in Theory and in Empirical Models," in Ralph Bryant, Dale Henderson, Gerald Holtham, Peter Hooper, and Steven Symansky, eds., Empirical Macroeconomics for Interdependent Economiess (Brookings Institution, 1988), pp. 17-26.

7. This result seems to hold when controlling for factors such as size of the economies, distance between the areas compared, and policy differences. See, for example, Tamim Bayoumi and Barry Eichengreen, "Shocking Aspects of European Monetary Integration," in Francisco Torres and Francesco Giavazzi, eds., Adjustment and Growth in the European Monetary Union (Cambridge University Press, 1993); and Todd Clark and Eric van Wincoop, "Borders and Business Cycles," Journal of International Economics, vol. 55 (October 2001), pp. 59-85.

8. Most estimates of the effect of small increases in trade intensity on output correlation are similarly small. See Jeffrey Frankel and Andrew Rose, "The Endogeneity of the Optimum Currency Area Criteria," Economic Journal, vol. 108 (July 1998), pp. 1009-25; Fabio Canova and Harris Dellas, "Trade Interdependence and the International Business Cycle," Journal of International Economics, vol. 34 (February 1993), pp. 23-47; and Clark and van Wincoop, "Borders and Business Cycles."

\section{A Change in the Nature of Shocks}

Even without increased integration, the correlation of economic growth across nations would rise if the type of shock that leads to common movements ("common shock") becomes more prominent or if country-specific shocks become less prominent. Common shocks could become more "prominent" in either or both of two ways: (1) if the size or frequency of the shocks increases and (2) if the sensitivity of national economies to the shocks increases.

A textbook example of a common shock is a rise in the world price of oil, which might be expected to cause a synchronized decline in output growth around the world. The synchronized decline in output growth in the United States and the other G-7 countries in the mid-1970s (see chart 1) is often attributed to the sharp rise in world oil prices at that time. Similarly, oil price increases may have played a role in the recent downturn-for example, the spot price of oil as measured by the price of a barrel of West Texas intermediate crude rose from just under $\$ 11$ in December 1998 to more than $\$ 34$ in March 2000." The global decline in the value of information technology stocks beginning in early 2000 has also been cited as a common shock contributing to the current recession.

As explanations for high correlation, more complete economic integration and increased prominence of common shocks differ in an important way. Because increased integration is probably here to stay, we would expect any of its effects on correlation to be long lasting. But if correlation is currently high because of common shocks, we would expect the high degree of correlation to persist only as long as the common shocks continue. A brief period in which common shocks are more prominent might lead to temporarily high correlation with few implications for the future. Sharp increases in the world price of oil, for example, played an important role in the economics of the 1970s and early 1980s but have been less prominent since then.

A less obvious source of increased correlation is a decrease in the prominence of idiosyncratic shocks-shocks affecting only one country. This source can be understood by looking at the formal definition of the correlation of growth rates, which is the covariance of the growth rates divided by the

9. For an argument that oil shocks are central in explaining recessions, see James Hamilton, "What is an Oil Shock?" University of California at San Diego (2000). A contrary view is provided by Robert B. Barsky and Lutz Kilian, "Do We Really Know that Oil Caused the Great Stagflation? A Monetary Alternative," NBER Macroeconomics Anmul 2001 (MIT Press, 2002). 


\title{
Correlation as a Measure of Co-movement
}

\author{
Correlation of growth of $\mathrm{A}$ and $\mathrm{B}=\frac{\text { Covariance of } \mathrm{A} \text { and } \mathrm{B}}{\text { Standard deviation of } \mathrm{A} \cdot \text { Standard deviation of } \mathrm{B}}$
}

Covariance in growth of countries A and B is a measure of the common variability in growth of $\mathrm{A}$ and $\mathrm{B}$.

Standard deviation of growth of country $\mathrm{A}$ is a measure of the variability of growth of country A.

Correlation can be viewed as the ratio of total common variation (covariance) in the two growth rates to a measure of total variation (the product of the standard deviations). The correlation between two variables is a number between -1 and 1 . A positive correlation between growth in coun- tries A and B means that when growth is strong in country $\mathrm{A}$ it also tends to be strong in country $\mathrm{B}$. A negative correlation means that when growth is strong in country $A$, growth tends to be weak in B. The magnitude of correlation is one measure of the degree of association between the growth of $\mathrm{A}$ and $\mathrm{B}$. A correlation of 1 between $\mathrm{A}$ and $\mathrm{B}$ means that the growth rates of the countries move entirely in lockstep. A correlation of zero means that growth in the two countries is unrelated; correlation of . $z$ implies moderate association. product of the standard deviations of each of the two growth rates (see box "Correlation as a Measure of Co-movement"). The standard deviation of a growth rate is a measure of its total variation. A decline in the prominence of idiosyncratic shocks in a country lowers the standard deviation of the country's economic growth. If, at the same time, common variation as measured by covariance is unchanged, then correlation rises.

The case of reduced prominence of idiosyncratic shocks is important to emphasize for two reasons. First, although an increase in correlation is commonly interpreted as an increase in the amount of common variation in the economies, an increase in correlation can also come, as just noted, from a decrease in idiosyncratic variation. To take an example, the growth rate of a country that follows erratic fiscal and monetary policies will become more correlated with the growth of other nations if it moves to a more stable policy. The rise in correlation in this case does not come from greater transmission of shocks or more prominent common shocks; rather, sources of common variation are unchanged, but idiosyncratic variation has been reduced. A rise in the correlation of economic growth rates due to an increase in common shocks and a rise due to a decrease in idiosyncratic shocks have different implications for public policy: A rise in correlation because of a greater prominence of adverse common shocks would be a matter for concern, but a rise in correlation because of a reduction in adverse idiosyncratic shocks would be beneficial.

The second reason to emphasize the case of idiosyncratic shocks is that it highlights the importance of a change in standard deviation for the measure of correlation (recall that a decline in idiosyncratic shocks reduces standard deviation). A consensus is growing that the standard deviation of economic growth in the United States has been falling in recent years. " Indeed, evidence suggests that the standard deviation of U.S. growth has fallen one-third or more since the early $1980 \mathrm{~s}$. The source of this reduction is not evident, but some of its implications for correlation are clear. If the covariance of U.S. growth with other nations is unchanged, the one-third reduction in the standard deviation of U.S. growth would imply that the correlation of U.S. growth with that of every other nation would be 50 percent greater than its earlier value. " If correlation has not risen so dramati-

10. See, for example, Margaret MeConnell and Gabriel PerezQuiros, "Output Fluctuations in the United States: What Has Changed Since the Early 1980's?" American Economic Review, vol. 90 (December 2000), pp. 1464-76; James Kahn, Margaret McConnell, and Gabriel Perez-Quiros, "The Reduced Volatility of the U.S. Economy: Policy or Progress?" Federal Reserve Bank of New York (2001); James Stock and Mark Watson, "Has the Business Cycle Changed and Why?" NBER Macroeconomics Annual 2002 (MIT Press, forthcoming); Shaghil Ahmed, Andrew Levin, and Beth Anne Wilson, "Recent U.S. Macroeconomic Stability: Good Policies, Good Practices, or Good Luck?" International Finance Discussion Paper 730 (Board of Governors of the Federal Reserve System, July 2002); Chang-Jin Kim, Charles Nelson, and Jeremy Piger, "The Less Volatile U.S. Economy: A Bayesian Investigation of Timing, Breadth, and Potential Explanations," International Finance Discussion Paper 707 (Board of Governors of the Federal Reserve System, August 2001); M. V. Cacdac Warnock and Francis E. Warnock, "The Declining Volatility of U.S. Employment: Was Arthur Burns Right?" International Finance Discussion Paper 677 (Board of Governors of the Federal Reserve System, August 2000); Olivier Blanchard and John Simon, "The Long and Large Decline in U.S. Output Volatility," Brookings Papers on Economic Activity, 1:2001, pp. 135-64; Thomas Helbling and Tamim Bayoumi, "G-7 Business Cycle Linkages Revisited," International Monetary Fund (2002).

11. Multiplying a standard deviation in the denominator of the correlation definition by $\forall$ implies that correlation is $\%$ of or is 50 percent greater than, its former level. 
cally, then either the covariance between the United States and other countries has decreased, or the standard deviation of growth abroad has increased, or both.

\section{Summary}

The most obvious explanation for an increase in the correlation of growth would probably be that linkages among economies have increased and, thus, ups and downs in one economy are now transmitted more to other economies. However, two other explanations - an increased prominence of common shocks or a decreased prominence of idiosyncratic shocks-may be at least as important in explaining changes in correlation.

\section{THE CORRELATION OF \\ U.S. AND FOREIGN G-7 GROWTH.}

In this section, we analyze estimates of correlation of U.S. economic growth with that of the other G-7 nations. The behavior of the average foreign G-7 growth rate is representative of the behavior of the data for each of the six countries, but it masks some important differences. After considering the average, we turn to the correlation of U.S. growth with each other country individually.

Using standard formulas, an estimate of correlation can be computed over any time period. An analysis that compares average correlations over selected time periods supports the view that correlation has increased recently. This analysis estimates the correlation between U.S. quarterly growth in GDP and the average of quarterly growth for the other G-7 countries over three subperiods between 1970 and 2002: the most recent 2! 2 years for which data are available (1999:Q4 to 2002:Q1) and each half of the earlier part of the sample period (chart 4). ${ }^{12}$ For the entire period from 1970:Q2 to 2002:Q1, the correlation in growth rates is 0.44 (value not shown in chart). The estimated correlation is considerably higher in the recent $2 \frac{1}{2}$ years $(0.55)$ than in the first or second halves of the earlier sample $(0.43$ and 0.28 respectively). However, comparing the recent correlation estimate calculated over a brief period to earlier estimates calculated over much long periods may give a false impression that the recent rise is unique. The possibility that the recent level may merely reflect a historically normal fluctuation could be hid-

12. The first quarterly GDP level used is for 1970:Q1, and hence the first quarterly growth value is for 1970:Q2.
4. Correlation of change in real GDP in the United States with the average change in the other G-7 countries, selected periods, 1970-2002

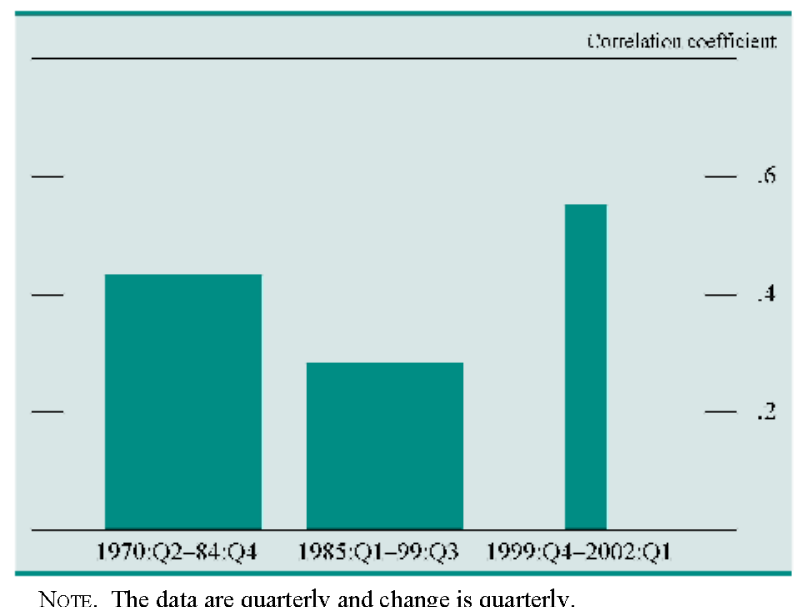

NoTE. The data are quarterly and change is quarterly.

den in the earlier estimates formed over longer periods..$^{13}$

\section{The Historical Pattern of Estimated Correlation}

One way to show a more reliable picture is to plot the correlation estimated for overlapping (or "rolling") five-year periods that start in 1970:Q2 and roll forward one quarter at a time. Thus, the correlation estimated for 1975:Q1 is calculated over the five years (twenty quarters) beginning in 1970:Q2 and ending in 1975:Q1

Measuring correlation over a series of rolling fiveyear periods (chart 5, upper panel) gives a more detailed depiction of correlation over the past thirty years-and one that is much different from that in chart 4. Estimated correlation fluctuates a great deal over the period, ranging from a high of 0.80 to a low of -0.23 . In the mid-1970s, mid-1980s, and early $1990 \mathrm{~s}$, the estimated correlation consistently rises and reaches a local maximum within the five years of the end of a recession, so that the five-year period of data used in calculating the correlation contains the recession period. ${ }^{14}$ These local maximums are quite

13. These data include the 2002 annual August revision to GDP for the United States. Data for the most recent recession in the United States as well as in the rest of the G-7 are subject to still further revision.

14. The National Bureau of Economic Research (NBER) is a nonpartisan research institution that determines the beginnings (business cycle peaks) and ends (business cycle troughs) of recessionsperiods when economic activity actually declines. More information about how the NBER chooses business cycle dates is available on its web site at www.nber.org. See also general note to chart 1 . 
5. Summary measures of change in real GDP in the United States and the average change in the other G-7 countries, rolling five-year periods, 1975-2002:Q1

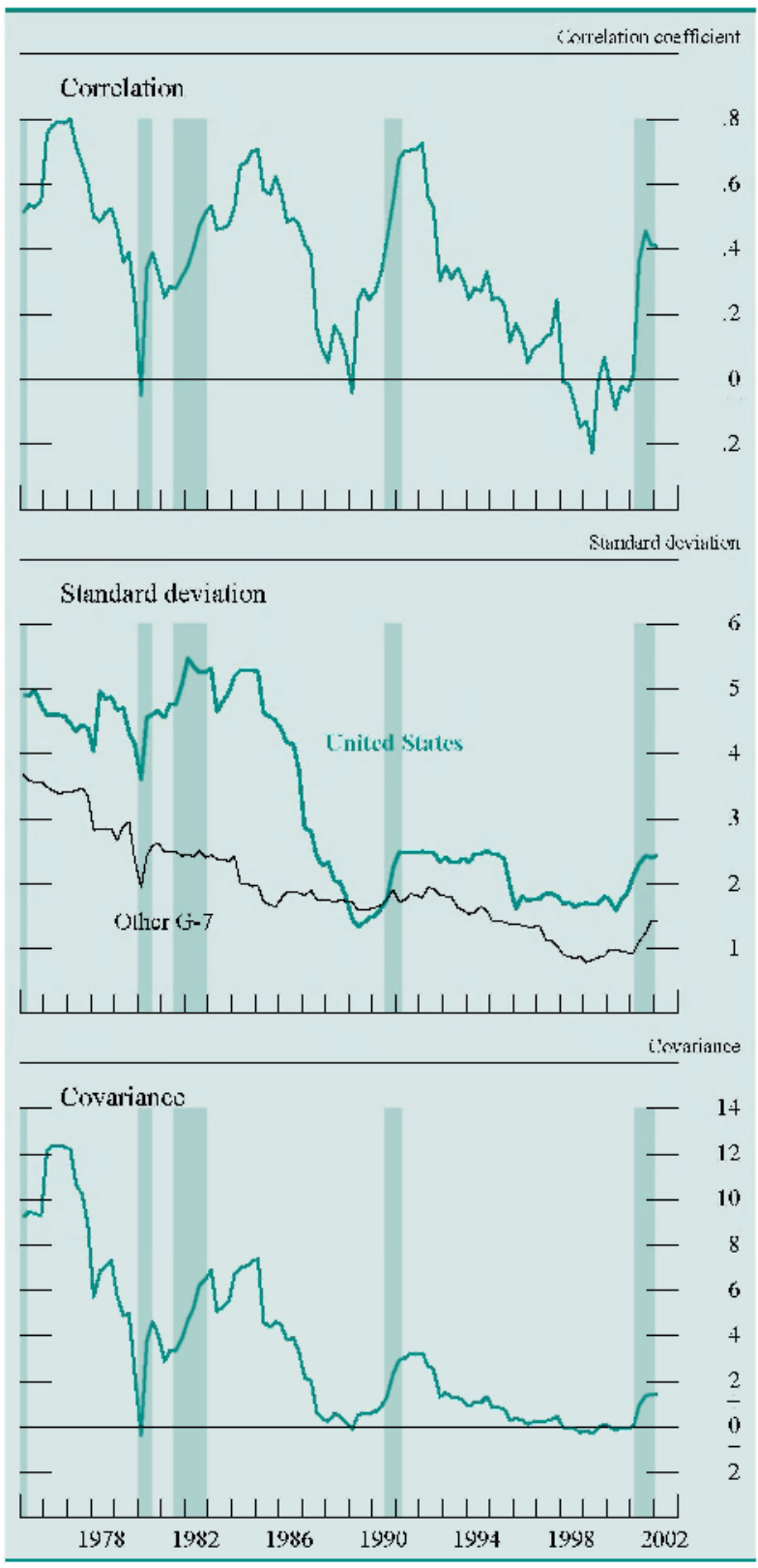

NoTE. The data are quarterly and change is quarterly. Values for each quarter are calculated over the five years ending in that quarter. For description of shaded bars, see general note to chart 1 .

high (above 0.70). Between each of the periods of high correlation have been brief periods in which estimated correlation is negative.

Although the recent correlations shown in both chart 4 and chart 5 are relatively high, chart 5 shows that, earlier in the period, correlation reached even higher levels than it has of late. The recent pattern of increase around the time of a U.S. recession seems roughly in line with historical experience. Indeed, if any change in correlation is evident, it is a slight downward trend over the whole period. Hence, we see little evidence of a period of permanently higher correlation in these data.

\section{The Recent Record on Standard Deviations and Covariance in G-7 Growth}

In contrast to the correlation data, the standard deviations of U.S. growth and average foreign G-7 growth show a clear pattern of change (chart 5, middle panel). As noted earlier, the standard deviation of U.S. GDP growth seems to have fallen sharply in the mid-1980s and has since fluctuated at less than $2 / 3$ of its former level. The standard deviation of foreign G-7 growth also appears to have fallen over this period. All else equal, the decline in the standard deviations of U.S. and foreign G-7 growth would imply a steady rise in correlation over the period, which we have not observed. Given the definition of correlation, the only other possibility is that covariance also fell (chart 5, bottom panel). The decline in the U.S. standard deviation has been widely reported, but the reduction in the standard deviations of growth in the other G-7 nations and the contemporaneous fall in covariance with U.S. growth have received less notice.

No consensus has emerged as to the source of these changes in standard deviation and covariance. Generally, the standard deviation in growth of a country will fall if some source of variation is removed; covariance between the growth rates of two countries will fall at the same time if some of the variation that is being removed is common variation. Correlation will be roughly unchanged if the decrease in standard deviation is attributable in roughly even proportions to declines in common and idiosyncratic variation, so that the share of variation that is common is unchanged.

Three explanations have been advanced as possible causes of the recent reductions in standard deviation and covariance. The first is a decreased prominence of common shocks. A reduction in the frequency of oil price shocks or in the G-7 economies' response to those shocks, for example, would remove a common source of variation in G-7 economies and thereby potentially reduce both the standard deviations and covariance. But because this change falls mainly on common variation, it would tend to lower correlation.

The second development is improvements in inventory management. If businesses worldwide are using advances in information technology to better 
manage inventories, they may thereby ameliorate one source of variability in output growth. Better inventory management might be expected to reduce the effects both of common shocks and of idiosyncratic shocks and hence might be expected to have neutral implications for correlation.

The third commonly discussed possibility is that improved government policy since the early 1980s has facilitated more steady growth. Proponents of this view note, for example, that inflation in the G-7 economies has generally been lower and less variable recently than it was in the 1970 s and early 1980 s. As with better inventory management, improved management of national economies might tend to have neutral implications for correlation because it could moderate growth variability due both to common and to idiosyncratic shocks.

The importance of these factors in explaining the fall in the standard deviations and covariances of growth in the G-7 is unresolved. The search for additional explanations continues. ${ }^{15}$

Although the causes remain uncertain, the fall in the standard deviations and covariances of growth rates complicates the task of detecting other influences on correlation. A small and gradual change in correlation due to ongoing gradual changes in integration, for example, could easily be hidden by other effects that are changing the numerator and denominator of correlation.

Overall, we reach the following conclusions from our analysis. Over the period since 1970, estimated correlation of GDP growth between the United States and the other G-7 countries has fluctuated, reaching peaks after recessions in the United States. Recent high levels of correlation are consistent with this overall pattern. Nonetheless, drawing conclusions about correlation is complicated by the fact that the standard deviations of growth in the United States and in the foreign G-7 seem to have declined. The effect of the decline of standard deviations on the correlation of growth has been roughly offset by a decrease in the covariance of U.S. growth with that of the other G-7 economies. In light of these facts, the evidence does not provide support for the view that increasing integration has fundamentally raised the correlation of U.S. growth with growth in the other G-7 economies. In the following sections, we subject these basic conclusions to various challenges.

15. One further example of an alternative explanation is that a reduction in capital market imperfections might have lessened the effects of ishocks on the economy. For a discussion of these and other explanations, see the articles cited in note 10 .
Comparing the United States with Each of the Other G-7 Countries

Again using a five-year rolling interval and quarterly data for the past thirty years, we examined the correlation of growth in real GDP in the United States with the growth of each of the other G-7 economies. ${ }^{16}$ The analysis shows that the correlation with five of the six other countries is generally positive (chart 6) and has neither a clear upward nor downward trend over the whole sample period. Japan is the exception, having had a persistently negative correlation with the United States since the early 1990s as Japanese economic growth slumped and the U.S. economy boomed. The correlation of each economy with the United States generally rises around the time of U.S. recessions.

Although the most recent estimated correlations are higher than in the mid-1990s, none surpasses the peaks attained around the time of earlier recessions. In short, over the past thirty years, the U.S. economy has had a history of moving somewhat in tandem with those of the other G-7 countries, whether the six are viewed collectively or individually; the recent rise in co-movement is largely in line with that history and does not provide a basis for concluding that the recent rise in correlation signals a new period of permanently higher correlation.

As noted, the correlation between the growth rates of two economies is the ratio of the covariance of the growth rates in the two countries divided by the product of their standard deviations. The standard deviation of quarterly growth in real GDP, not only for the United States but also for each foreign G-7 economy except Japan, generally fell over the period (chart 7). While the decline in the U.S. standard deviation appears to have come mainly in a sharp drop in the early $1980 \mathrm{~s}$, the decline in much of the foreign G-7 seems to have been more gradual. Especially in the case of France, the decline is also smaller in magnitude. All else equal, this fall in standard deviation at home and abroad would raise the correlation of U.S. growth with that of the foreign G-7. The estimated correlation between growth rates in the United States and the rest of the G-7 shows no sharp increase as standard deviations fell because the estimated covariance between the U.S. and foreign G-7 growth rates has also fallen (chart 8). Once again,

\footnotetext{
16. The conclusions regarding Germany must be viewed with caution because of the GDP measurement issues surrounding German unification. Our growth rate data for Germany are for the former West German area through 1991 and for unified Germany thereafter.
} 
6. Correlation of change in real GDP in the United States with the change in each of the other G-7 countries, rolling five-year periods, 1975-2002:Q1

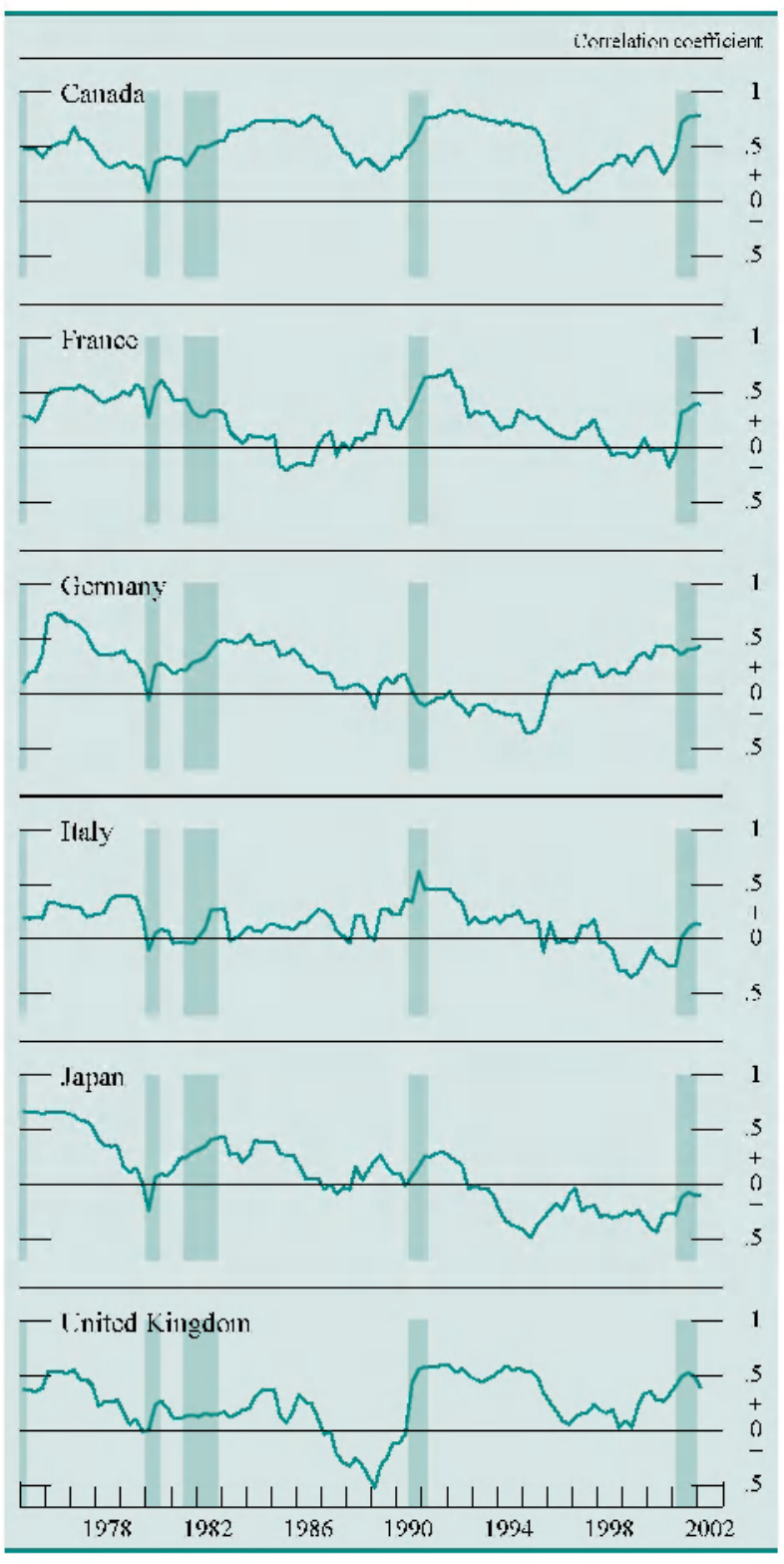

Note. See note to chart 5 .

the estimated covariance of growth rates with those in the United States are considerably lower from the mid-1980s onward when compared with the earlier period.

\section{Extensions and Limitations of the Central Conclusions}

The evidence just presented on correlation was for a single measure of economic activity (GDP), one
7. Standard deviations of change in real GDP in each of the G-7 countries, rolling five-year periods, 1975-2002:Q1

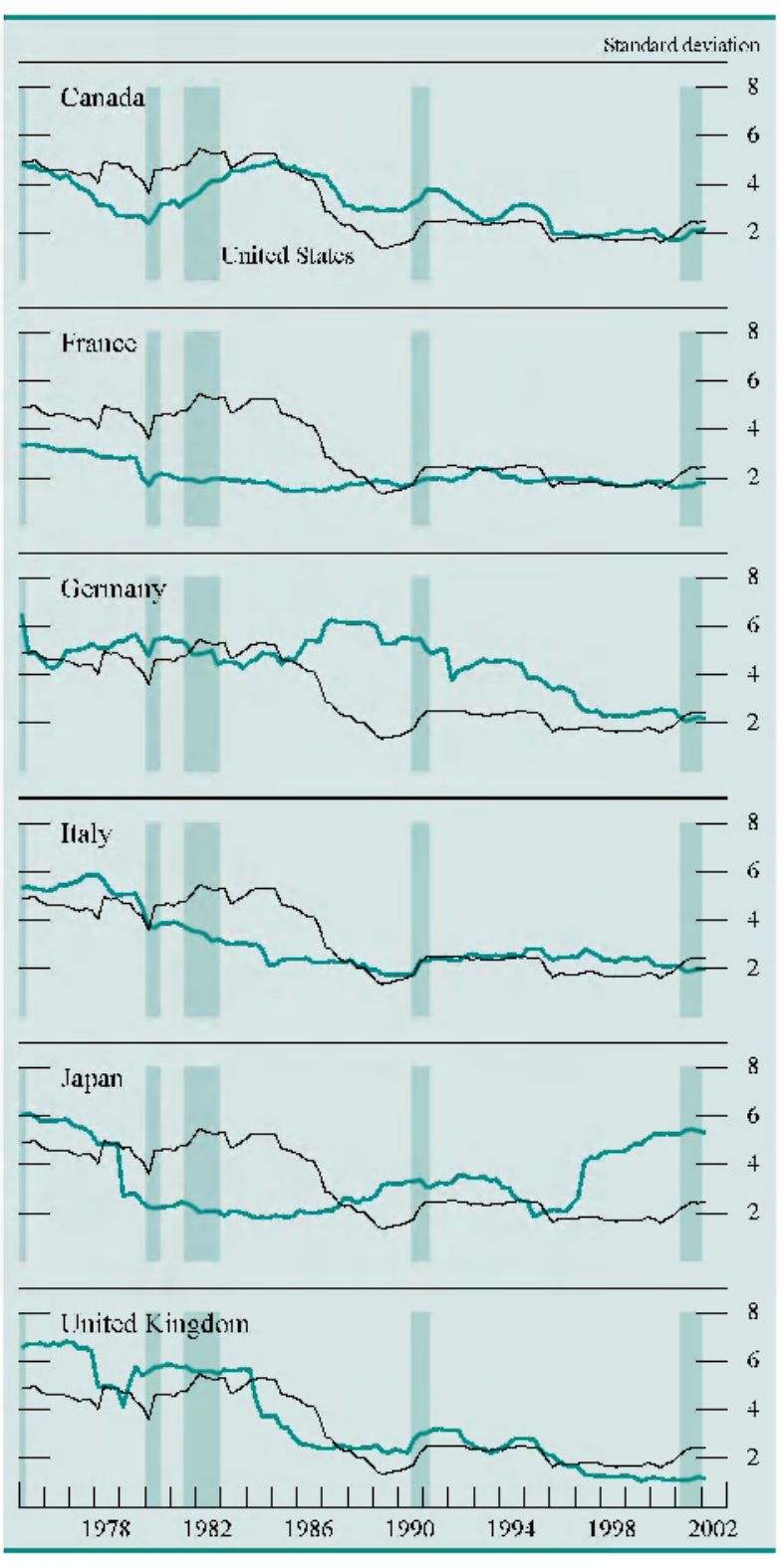

NoTE. See note to chart 5 .

growth interval (quarterly), and one type of period for measuring correlation (five-year periods that roll forward one quarter at a time). Different conclusions might arise if one were to consider other ways of measuring the correlation of economic activity. To test the robustness of our basic conclusions, we examined thirty-six measures of correlation in activity by applying nine correlation measures (correlations in quarterly growth, four-quarter growth, and a gap measure over two-and-one-half-year, five-year, and ten-year rolling periods) to four real economic 
8. Covariance of change in real GDP in the United States with the change in each of the other G-7 countries, rolling five-year periods, 1975-2002:Q1

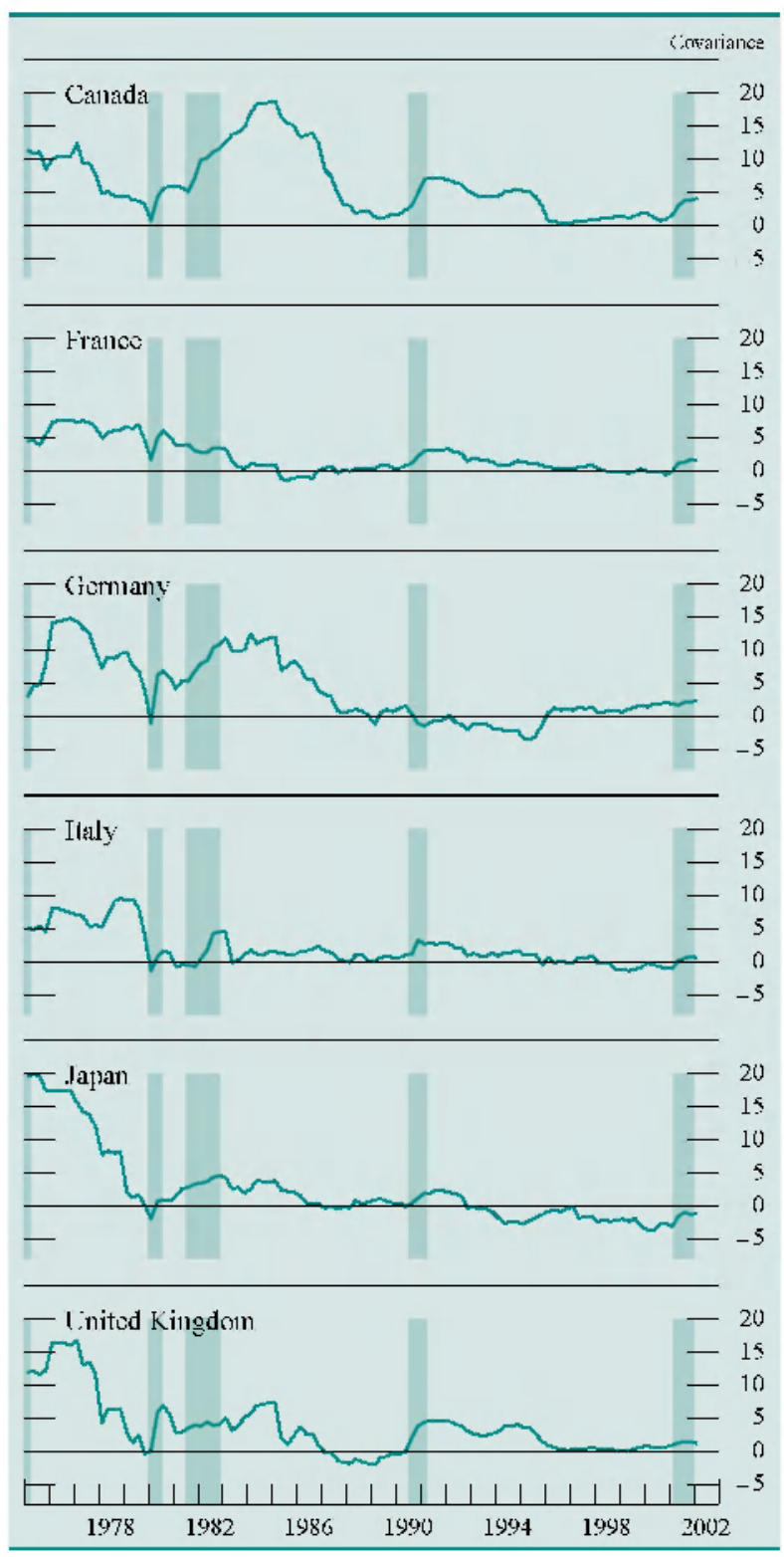

NOTE. See note to chart 5 .

aggregates: GDP, consumption, investment, and industrial production. ${ }^{17}$

These alternative measures offer several potential insights. Both the output gap measure and the fourquarter growth rate will capture longer-term movements better than does the quarterly growth rate of GDP. By focusing on the correlation of output gaps,

17. For any variable, the associated gap measure is defined as the logarithm of the variable minus the trend in the logarithm of the variable calculated using the Hodrick-Prescott filter. The trend calculated in this way fluctuates through time.
9. Correlation of output gaps in the United States with the output gaps in each of the other G-7 countries, rolling five-year periods, 1975-2002:Q1
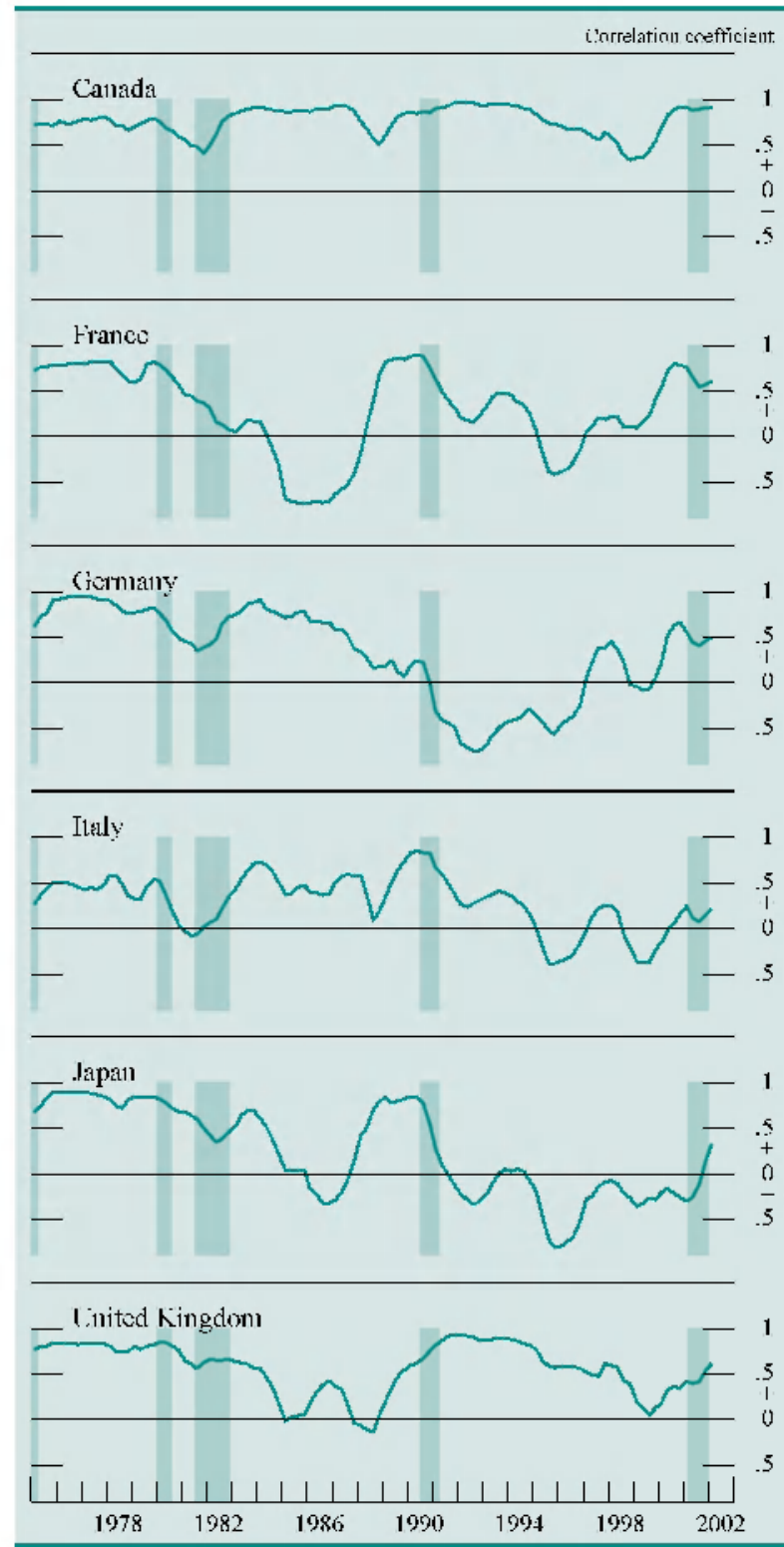

NotE. For method of calculating the output gaps, see text note 17. See also note to chart 5.

rather than the correlation of GDP growth, we may also better capture business cycle variation in these economies. Consumption and investment are of interest because these broad components of GDP may be more subject to international linkages than is, say, the government spending component of GDP. Industrial production is more volatile than other components of output such as services. Further, industrial output is generally tradeable across borders. Thus, an increase in correlation due to economic integration might show up first in industrial production. 
With almost all of the thirty-six measures, we found that estimated correlation in the recent period has not exceeded the levels attained earlier in the sample. For example, the pattern of fluctuation of output gap correlations (chart 9) is somewhat different from that of correlation in quarterly GDP growth. In particular, the correlation in output gaps does not rise as consistently during U.S. recessions. Still, the overall conclusion remains the same: Estimated correlation fluctuates and has not recently exceeded earlier peaks. We can summarize the results of all the measures in the following way: In only a few cases has correlation recently surpassed earlier peaks, usually by only a slight amount, and no clear or consistent pattern of increased correlation emerges across countries or measures of correlation.

Some analysts have cited a slight trend decline in the cross-sectional standard deviation of GDP growth in the G-7 economies over the period since the 1970s as evidence of a rise in the correlation of GDP growth (chart 10). ${ }^{18}$ This trend decline in crosssectional standard deviation could come from a rise in correlation - if growth were more correlated across countries, the individual growth rates should be less dispersed at any point in time. However, the crosssectional standard deviation will also fall if correlation is constant and the individual standard deviations fall. Thus, the fall in the cross-sectional standard deviation is consistent with our basic conclusion that standard deviations have fallen while correlation has been roughly unchanged.

18. For any calendar quarter, the cross-sectional standard deviation of growth is the standard deviation of the growth rates of the seven G-7 countries in that quarter.

10. Cross-sectional standard deviation of change in real GDP of the G-7, 1971-2002:Q1

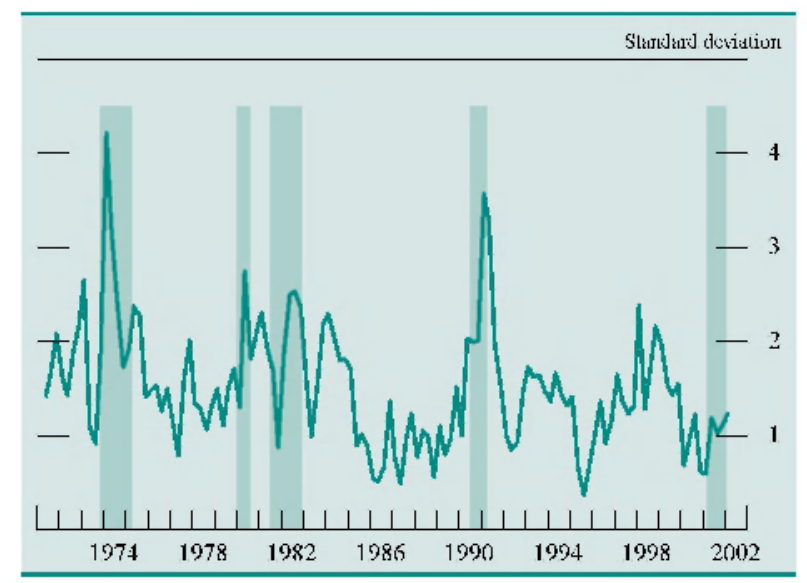

NotE. The data are quarterly and change is for four quarters. The cross-sectional standard deviation in any quarter is the standard deviation of the four-quarter change in all of the G-7 countries in that quarter.
Finally, we highlight two limitations of our results. Our many different measures of correlation of economic activity among the G-7 countries produce basically consistent results, but those conclusions may or may not apply to the linkages between the United States and, say, emerging-market economies. Second, and more broadly, a change in the correlation of national economic growth rates is not likely to be visible unless the change is very large or has been in place for a decade or more. For example, if a modest permanent increase in correlation occurred in the late 1990 s, our tools would not discover it until the higher estimated correlation during the recent recession persisted well into the future.

\section{SUMMARY}

Various linkages among economies are becoming stronger. Trade-to-GDP ratios are rising, financial markets are becoming increasingly integrated, and advances in global telecommunications might cause less tangible factors, such as consumer and business confidence, to become more closely linked. No consensus exists, however, as to how large an effect these factors should have on the correlation between GDP growth in the United States and in the other G-7 nations. Furthermore, any effect of these factors on correlation would very likely be gradual.

At this time, any changes in correlation due to increased integration do not show clearly in the data. The correlation of U.S. GDP growth with that of the foreign G-7 economies in the recent U.S. recession has been roughly in line with the experience around the time of earlier recessions. Estimated correlation has risen from its level during the previous expansion, but not in a way that clearly distinguishes this recession from earlier ones. Overall, we find no evidence to indicate that the recent rise in correlation signals a future of permanently higher synchronization of national growth rates.

The most dramatic change over the period since the early 1980 s seems to have been a fall in both the standard deviation of growth in most G-7 economies and a contemporaneous fall in the covariance of U.S. and foreign G-7 growth. The source of this change is the subject of ongoing debate. Possible explanations include a decrease in the prominence of common shocks to the global economy, improved management techniques by firms, and a better macroeconomic policy environment. It remains to be seen how these factors, combined with continuing increases in economic integration, may affect the co-movement of U.S. economic growth with that of the other $\mathrm{G}-7$ economies in the future. 